\title{
AMERICAN JOURNAL OF OPHTHALMOLOGY
}

Vol. 3

OCTOBER, 1920

No. 10

\section{RETICULAR KERATITIS}

W. Gordon M. Byers, M.D.

MONTREAI, CANADA.

This is the detailed report of a case, presenting novel clinical findings; with special reference to the bearing of these findings upon the etiology of reticular keratitis.

Among the rare diseases of the cornea, lattice-like or reticular keratitis occupies a foremost place in point of interest. The morphologic features of this entity are now fairly well defined, and a little work has been done on its morbid histology; but a full explanation of the curious disorder awaits the chance of an examination of an eye affected in this way, as well as the solution of some of the most difficult problems in ocular pathology.

Some novel clinical findings in the following case seem, in the meantime, however, to throw some light upon the origin of the corneal changes, and to point to the general factors which may predispose to the local condition. Especially is this true if one studies the case in connection with observations on closely related keratitides.

The patient was a physician, aged 47 , who began to feel about a year previously that he needed stronger glasses for reading, and that he was shooting badly. He stated also that he saw three images with either eye. A white line against a black background, for instance, appeared in triplicate, the lateral lines being about equidistant from, but not nearly so clearly defined as, the middle one. As a consequence people looked broader and stouter owing to overlapping of the images. There was no history of injury, and no other complaints (including hemeralopia and nyctalopia).

The man had had measles and scarlet fever in childhood, and typhoid at fourteen. After that no illness until 1912, when for 11 months he had attacks of renal colic occasioned by the slow passage of a stone. A cancer of the right breast, which seemed to follow a fall on the side, rupturing a rib, was removed in April, 1917.

In the family history it was to be noted that there had been no hereditary eye trouble in the three generations of which the patient had knowledge. There did seem to be, however, a tendency to malignancy and to arterial degeneration. Two of his maternal aunts, as well as a maternal cousin (female), had died of cancer; while both his father's father and mother, and one paternal aunt, had succumbed to apoplexy. His father died at 62 of diabetes, after being afflicted with this condition for 10 years; his mother of cardiorenal disease at 44.

I aking in particularly the central area of the cornex, and without the slightest sign of any irritation or congestion, one saw the changes which have been described under the term "reticular" or "lattice-like" keratitis, and are more fully dealt with later in this report. I had never seen a case of this kind, but I immediately recognized it from Hudson's illustration (1), which had stamped itself on my memory.

The accompanying plate from a sketch by Dr. Gross gives an approximate idea of the distribution of the opacities as seen by transillumination, and by oblique illumination.

With the corneal microscope, in the short period I was able to have the patient under observation, I satisfied myself that the lines were in or immediately beneath Bowman's membrane. I could not determine with certainty what position the opácities occupied in relation to the surface of the cornea. They seemed at times to be depressed below, at others raised above, the epithelial coverings. I think both conditions existed. In any 
case the unevenness of the surface was everywhere shown by a slight, but definite, distortion of the mires of the ophthalmometer.

The threads of the reticulum seemed to spring directly from one another; but rarely one could see lines, more deeply situated, crossing beneath those more superficially placed. Not infrequently one came across streaks, the continuity of which was occupied for a short distance by a chain of minute, sand-like beads of crystalline substance. These were particularly well seen when the pupil was dilated.

The pupils, while equal and regular, were unusually active to light. There were no changes in the fundi. The fields of vision were full; and central vision was as follows:

R., With-cyl. 1.0 D. axis $90,6 / 12$.

L., With-cyl, 1.0 D. axis $75,6 / 12$.

With + sphere 1.5 D. added, Sn.1. with each eye at $12^{\prime \prime}$. At the first consultation tension was as follows: $R ., 15$ mm. Hg.; L., $13 \mathrm{~mm}$. Hg. A year later (after twclve months of great activity), the doctor again unselfishly submitted to a further reading of tension, which was found to equal on both sides about 13.5 $\mathrm{mm}$. Hg.

The systemic examination carried out for me by Dr. Cushing yielded the following facts: General condition good; patient considerably over weight (197 lbs.; no change in three years). Lungs normal. Heart normal, except for occasional ventricular extra systoles; no evident arteriosclerosis; blood pressure 135 -90; abdomen negative; digestive system normal. The faintest trace of sugar in the urine; otherwise examination of the kidneys negative. Nothing found anywhere to suggest past or present tuberculosis. Wassermann, etc., negative.

Summarizing, Dr. Cushing wrote as follows: "Altho nothing definite was found, still the excess of abdominal fat, missed beats in the heart, recent carcinoma, and renal calculus give the impression of a man past his prime and showing signs of degeneration."

\section{REMARKS.}

Since Dimmer's paper (2), the linear opacities in reticular keratitis have been attributed to rucking of Bowman's membrane. Close inspection of the cornea with binocular magnification would probably convince anyone of the correctness of this view. The changes are certainly not more superficial, because they persist after exfoliation of the epithelium. On the other hand, the unevenness of the corneal surface, the refractive nature of the lines, and particularly their transparency in the direction of their course, all speak in favor of foldings of Bowman's membrane.

Now folding of Bowman's membrane is a well recognized and, in my experience, not uncommon microscopic finding in soft, atrophic eyeballs. The condition is clearly shown in association with corrugation of Descemet's membrane (Fig. 1.), in the accompanying microphotograph of the cornea of an eyeball greatly shrunken from plastic uveitis. I did not see this globe before its removal, and there are singularly few observations in the literature regarding the clinical appearances produced by the bucklings in Bowman's membrane. Parsons (3), without describing them, mentions having seen striate opacities from this cause, and quotes the case of Schirmer (4), - that of "a shrunken globe, in which the cornea was much diminished in size, hazy, and traversed by fan-like stripes, diverging above, where they did not reach the corneal margin, and ending below in a horizontal, slightly bent, gray line. In horizontal sections, there were six waves in the epithelial surface, below which were sharp triangular depressions in Bowman's membrane, which was intact."

More important are the observations of Spicer (5). This writer described in 1916, under the name of superficial linear keratitis, a series of cases in which, with pain and congestion, a number of superficial ridges of epithelium suddenly made their appearance in the cornea. These ridges were raised from the general level of the corneal surface; were, for the most part, vertical in arrangement; and gray in color, with tapering ends, not reaching to the limbus. Under magnification, the ridges were seen to be double contoured with a comparatively clear center 
Almost always, during at least some portion of the attack, there was a softening of the eye, tension falling to- 1 , and often to -2 . The attack itself lasted for a few days to a week or longer; and, as the ridges disappeared, the vision recov- diminished tension has not heretofore been made out in these cases cannot be used as an argument against the supposition; for we may well have had in them, as in chronic glaucoma, variations so slight as to call for the more sensitive

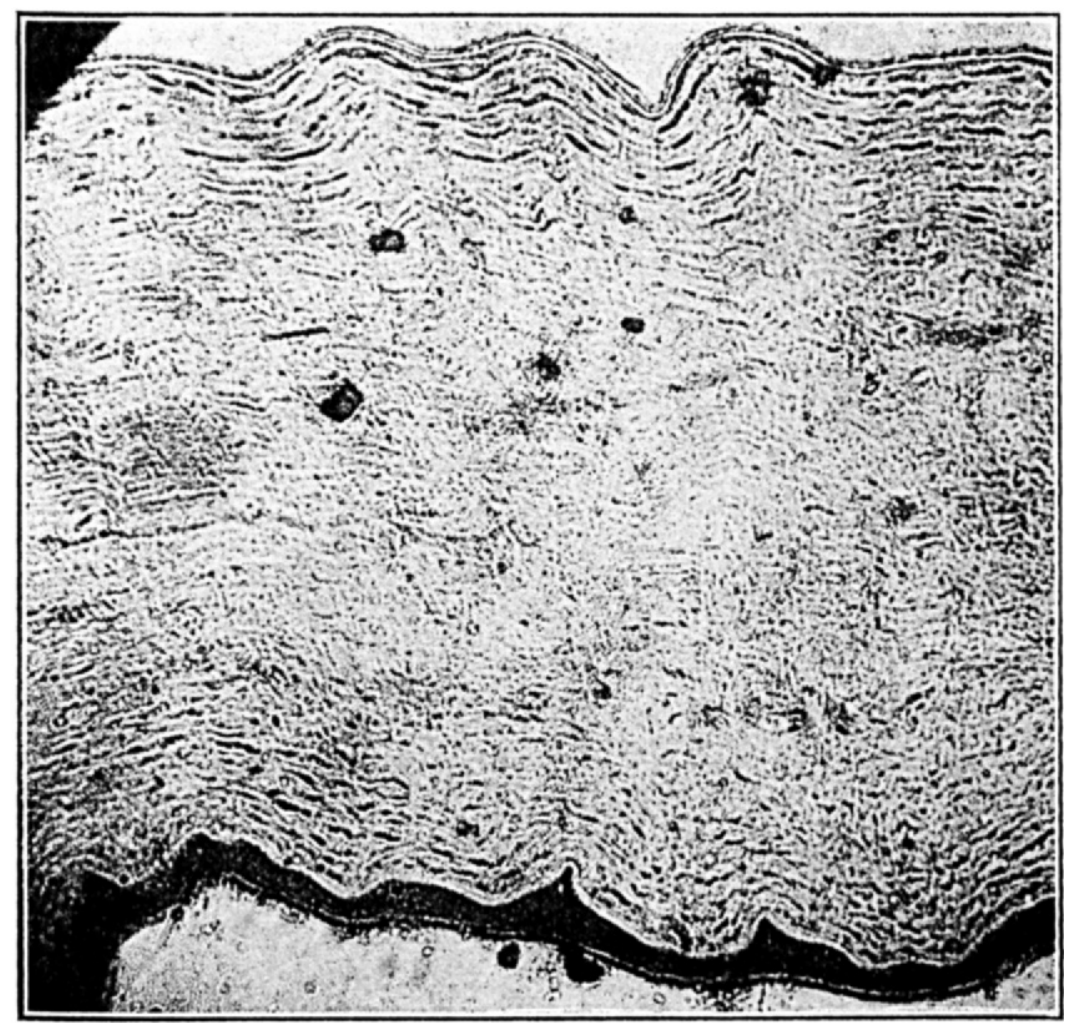

Fig. 1-Section of cornea showing corrugations of Bowman's membrane in association with marked rucking of Descemet's membrane.

ered and the tension became normal again.

Microscopic examination of two eyes by Affleck showed that the linear opacities were due to ridges in Bowman's membrane. The ridges varied in appearance in different places; but they were always characterized by the presence of new fibrous tissue in the immediately underlying substantia propria.

In the light of this evidence, and the finding of the hypotonia in my case, one is justified in advancing the hypothesis that reticular keratitis has its origin in lowered intraocular tension; and the same would hold for nodular and fleck-shaped keratitis if the view of Fehr (6) be correct, that the three conditions are but phases of a single entity. The fact that tonometer for detection. The complicated arrangement of the corneal opacities in retıcular keratitis bespeaks a lowgrade hypotonia of long standing; in contrast with the coarser changes in Spicer's cases, which were characterized by sudden reductions of comparatively short duration. We may have, in a word, in this group of cases, underlying hypotonias which correspond to acute and chronic glaucoma.

Incidentally it will be interesting to observe if eyeballs with greatly diminished tension following sclero-corneal trephining will develop changes similar to those in reticular keratitis. In the few cases thus affected among my own patients I have been unable, however, to detect anything of a like nature. 
The myopic astigmatism contrary to the rule is another point in the present case which favors the hypothesis of hypotonia; for, granting diminished tension, the increased corneal curvature would naturally be greater between the stronger pair of opposing muscles. Biber's case (7) showed the same error of refraction, which might be more carefully looked for in the future. In the left eye of my patient, the lines could be plainly seen to correspond rather closely to the oblique axis of the cylinder (See Plate IX).

The crystalline beads can be interpreted in other ways, e. g., as the terminal phase of a hyalin degeneration, or as detritus following the nutritional death of cellular elements; but, more probably, they are residual from a preexistant transudation of corneal lymph, which may well have been into clefts created by a. separation of Bowman's membrane from the substantia propria. Whatever view we adopt, we might surmise further that these bodies (or even a lymph with a more concentrated saline content) are responsible, thru irritation, for the connective tissue deposits observed by Affleck; and that the connective tissue in turn is the cause of the wide spread graying of the cornea that marks the later stages of reticular keratitis and the related keratitides. Taking as a whole the few observations that have been made in connection with this group of cases, we have in the crystalline, hyalin, and connective tissue deposits exactly those changes one would expect to find as the result of a stasis associated with hypotonia.

Studying the cases of reticular keratitis that have heretofore been reported, one feels that the systemic examinations have been inadequate. Where possible every patient affected in this way should be exhatustively studied, preferably in a metabolic ward, with a view to detecting disturbances that might possibly underlie the hypotonia. In the hereditary groups, hereditary defects might be discovered.

Following the lead suggested by the slight glycosuria in my case, and having in mind the observations of Riesman (8) and others regarding the association of hypotonia with diabetic coma, I investigated, with the assistance of $\mathrm{Dr} . \mathrm{E}$. A. McCusker, the ocular tension in a number of cases of diabetes in the metabolic ward. In these we found that the average reading was slightly below the normal lower limit. Another series of readings in ambulatory diabetics (former in-patients in attendance as out-patients) gave, however, only normal findings. This suggested to me that rest and confinement were responsible for the low readings in the first group; and this observation was confirmed by similar low figures in a number of surgical patients who were incapacitated solely by fracture and the like. The number of cases studied in this way is too few to permit one to dogmatize; but the assumption that the intraocular tension, in keeping with the general blood pressure, is lowered by rest is obvious in any case. One has here an indication both for glaucoma and hypotonia (reticular keratitis). In the present case it is apparent that retardation of the process could only follow a betterment of the physical condition thru massage, out-of-door exercise, diet, and the like.

That neither reticular keratitis nor any of the related conditions is a true inflammation is, apart from the findings enumerated, evidenced by the fact that at no time in their course is there new-vessel formation; and that congestion is present only in response to denudation of the epithelium, or in the later stages, perhaps as the result of the irritation of which I have spoken. The word keratitis should, therefore, be abandoned. In its place one could employ the term anterior (or superficial) corneal corrugations (or corrugations of Bowman's membrane), from acute or chronic hypotonia; in contradistinction to the posterior (or deepseated) corneal corrugations (or corrugations of Descemet's membrane), from diminished tension, which are with even less reason covered by the appellation keratitis striata. Classic equivalents of these terms are easily.coined. 
REFERENCES.

1. Hudson: Tr. Oph. Soc. U. K., Vol. XXIX, p. 11, 1909.

2. Dimmer: Zeitschrift für Augenh., Vol. II, p. 354, 1899.

3. Parsons: Pathology of the eye, Vol. I, pt. 1, p. 182.

4. Schirmer: Archiv für Ophth., Vol. X LII, pt. 3, 1896.

5. Spicer and Affleck: The Ophthalınosc ope, Vol. XIV, p. 116.

6. Fehr: Centralblätt für prakt. Augenh., Vol. XXVIII, p. 173, 1904.

7. Biber: Inaugural Dissertation, Zurich, 1890.

8. Riesman: Jour. A. M. A., Vol. LXVI, p. 95, 1916

\title{
PHAKOERISIS
}

\author{
IGNACIO BARRAQUER, M.D.
}

\section{BARCELONA, SPAIN}

The evolution of this operation with the difficulties overcome in perfecting it are here described. The manner of using the suction instrument by which one extracts the lens in its capsule is shown in the illustrations. The results attained in one thousand cases done after the method has been perfected are also reported. See also p. 770 .

There has been much written and succinctly the origin and the vicissitudes spoken on Phakoerisis, since I presented 'of the proceeding and instrument; until the first note to the Academies, and many I got a modus faciendi that allowed me

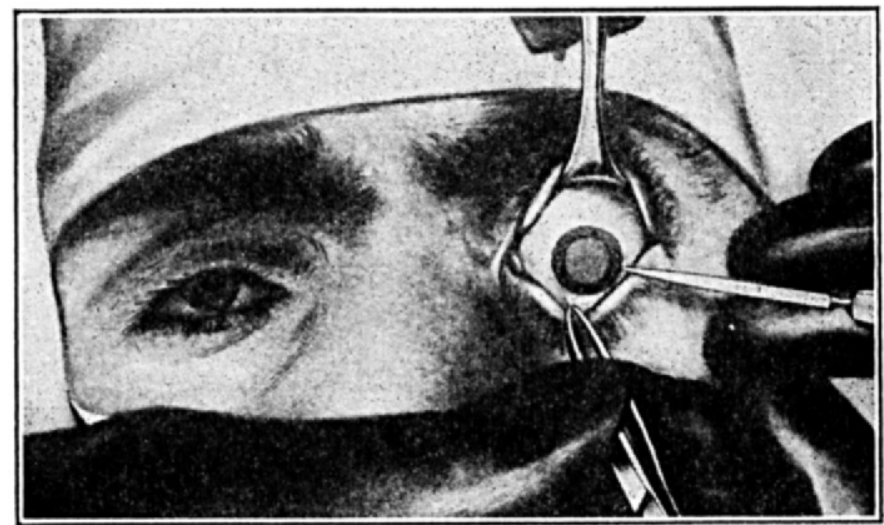

Fig. 1-Operation of phakoerisis (Barraquer); making puncture for corneal incision.

distinguished colleagues have been eager to experiment with a procedure for total extraction of cataracts of all varieties, with the minimum of accidents. But they could guide themselves only by the limited data I had previously published and by the accounts that they could read from the Spanish and foreign oculists, who saw me operating in the School of Medicine of Barcelona. They got a pseudoerisiphake from different makers, trying it without knowing my technic, and without knowledge of how I overcame the first difficulties.

With statistics of some thousand cases, I now have the pleasure of explaining to obtain excellent results in the cases that I now have the honor to report.

Convinced that we should not make partial extractions, on account of certain imperfections of the method, I tried during a series of months the procedures of total extraction, without complete satisfaction with any of them. I found better the operation which drew out the crystalline lens catching and drawing it, in spite of the brittleness of the capsule; nearly always converting this procedure into an extraction with cystotomy.

I sought an instrument in order to catch the crystalline lens with sufficient strength and to pull it out from the zo- 